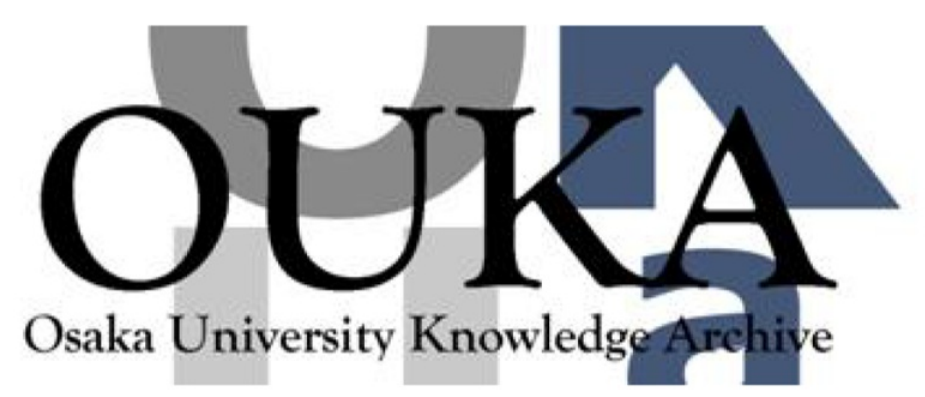

\begin{tabular}{|c|l|}
\hline Title & $\begin{array}{l}\text { Anomalous Reaction of Ary lmalononitri les with } \\
\text { Nitric Acid. Para-Directing Nature of } \\
\text { Dicyanomethy L Group and a Through-Ring } \\
\text { Nitro/aci-Nitro Tautomerism of 4- } \\
\text { Nitropheny lmalononitri le }\end{array}$ \\
\hline Author(s) & Suzuki, Hitomi; Koide, Hideki; Ogawa, Takuj i \\
\hline Citation & $\begin{array}{l}\text { BULLETIN OF THE CHEMICAL SOCIETY OF JAPAN. } \\
61(2) \text { p. 501-p.504 }\end{array}$ \\
\hline Issue Date & 1988-02 \\
\hline oaire:version & VoR \\
\hline URL & https://hdl.handle. net/11094/3258 \\
\hline rights & \\
\hline Note & \\
\hline
\end{tabular}

Osaka University Knowledge Archive : OUKA

https://ir. Library. osaka-u. ac. jp/

Osaka University 


\title{
Anomalous Reaction of Arylmalononitriles with Nitric Acid. Para-Directing Nature of Dicyanomethyl Group and a Through-Ring Nitro/aci- Nitro Tautomerism of 4-Nitrophenylmalononitrile ${ }^{1)}$
}

\author{
Hitomi Suzuki, * Hideki KoIDE, and Takuji Ogawn* \\ Department of Chemistry, Faculty of Science, Ehime University, Bunkyo-cho, Matsuyama 790
}

(Received September 11, 1987)

\begin{abstract}
Phenylmalononitrile reacts with nitric acid in dichloromethane at room temperature to afford 1,2-bis(4nitrophenyl)-1,1,2,2-tetracyanoethane as an initial product, which readily suffers oxidative cleavage to give 4-nitrobenzoyl cyanide. Contrary to common understanding, dicyanomethyl group exhibits no meta-directing property. 4-Nitrophenylmalononitrile is found to exist in two stable tautomeric forms, which undergo a facile nitro/aci-nitro interconversion across aromatic ring depending on the nature of solvent employed.
\end{abstract}

Successive replacement of methyl hydrogen atoms in toluene by chlorine atoms changes the directing effect of methyl group from predominant ortho/para orientation to predominant meta orientation. Thus, benzyl chloride gives on nitration ortho, meta, and para nitro derivatives in 34,14 , and $53 \%$ yields, respectively, ${ }^{2)}$ while the value is 7,65 , and $29 \%$ respectively for benzylidene trichloride. ${ }^{3)}$ Since the cyano group is more strongly deactivating than chlorine atom, it is quite understandable that the substitution of two cyano groups into methyl group of toluene would change the directing nature of methyl group from ortho/para into meta. Indeed, Flürsheim and Holmes nitrated phenylmalononitrile (1a) with nitric acid in acetic anhydride and obtained 68 and $32 \%$ respectively of meta and (ortho plus para) nitration products. ${ }^{4)}$ Their result has been taken as one of the examples of the substituentdependent modification of the electron-releasing property of methyl group and no doubts seem to have been thrown for more than half a century.

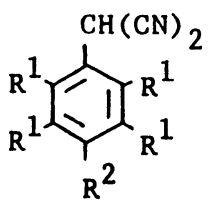

$\mathbf{l}$

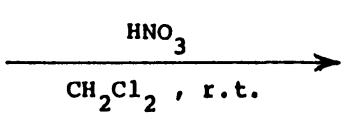

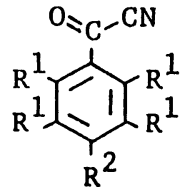

2
In the course of our continuing study on the nonconventional aromatic nitration, ${ }^{5}$ we had an occasion to reinvestigate the reaction of several arylmalononitriles with nitric acid under various conditions. Rather surprisingly, dinitrile la underwent a facile reaction both on aromatic ring and on side chain, giving 4-nitrobenzoyl cyanide (2c) in a good yield. In contrast to the literature report, ${ }^{4)}$ no 3 -nitro isomer could be detected in the product mixture.

A close inspection of this unexpected result revealed a new chemistry. Thus, when the reaction was quenched with water immediately after the addition of nitrating agent to a solution of la in dichloromethane at room temperature and the organic phase was worked up as usual, the product was a pale yellow crystalline solid which, after several recrystallization from $\mathrm{THF}$ and ether, melted at $156-157^{\circ} \mathrm{C}$ with decomposition. On dissolving into THF and acetone, it developed a pale yellow and an orange color respectively. Its solution in DMSO had a deep red color. Elemental analysis of this compound was consistent with the empirical formula $\mathrm{C}_{18} \mathrm{H}_{8} \mathrm{~N}_{6} \mathrm{O}_{4}$. The IR spectrum $(\mathrm{KBr})$ demonstrated the presence of cyano (2275 $\mathrm{cm}^{-1}$ ) and nitro groups $\left(1535\right.$ and $1360 \mathrm{~cm}^{-1}$ ), while its ${ }^{1} \mathrm{H}$ NMR spectrum $\left(100 \mathrm{MHz} ;\left(\mathrm{CD}_{3}\right)_{2} \mathrm{SO}\right)$ showed signals at $\delta 8.50$ and $7.70(\mathrm{~d} ; J=9.6 \mathrm{~Hz})$, relative intensity $1: 1$, due to vicinal aromatic protons. The ${ }^{13} \mathrm{CNMR}$ spectrum $\left(90 \mathrm{MHz} ;\left(\mathrm{CD}_{3}\right)_{2} \mathrm{SO}\right)$ indicated the presence of cyano groups $(\delta 110.0)$, substituted aromatic carbons $(\delta 129.4$ and 149.5$)$, unsubstituted aromatic carbons $(\delta$ 124.6 and 130.0$)$, and $\mathrm{sp}^{3}$ carbons $(\delta 52.8)$. These spectral evidences allowed for the compound the formulation of 1,2-bis(4-nitrophenyl)-1,1,2,2-tetracyanoethane (3). Its structure was further confirmed by direct comparison with an authentic specimen obtained from the oxidation of 4-nitrophenylmalononitrile (1c) with yellow mercury(II) oxide in dichloromethane at room temperature. When kept in contact with nitric acid in the same solvent, 3 was converted into benzoyl cyanide 2c. Under similar conditions, 4-methylphenylmalononitrile (lb) and 2,3,5,6-tetrachloro-4-methylphenylmalononitrile (1d) afforded the corresponding benzoyl cyanide $\mathbf{2 b}$ and $\mathbf{2 d}$ as the respective single product. Interestingly, dinitrile lc with two electron-withdrawing groups on aromatic ring reacted more easily with nitric acid than unsubstituted dinitrile la or methylsubstituted dinitrile $\mathbf{l b}$ to produce $\mathbf{2 c}$ in high yields.

We also carried out the nitration of la according to the procedure given in the literature. ${ }^{4)}$ The reaction proceeded quite rapidly, giving after $30 \mathrm{~min} 58 \%$ of $2 \mathrm{c}$ and $22 \%$ of 4-nitrobenzoic acid along with several minor products. No 3-nitro compounds could be obtained again. Although the reaction mechanism remains to be clarified, the oxidation of dinitrile lc to acyl cyanide $\mathbf{2 c}$ most likely involves a nitrated aci-nitro compound 4, which is formed via a $S_{\mathrm{E}} 2^{\prime}$ type process in which the attack of an electrophile occurs on the oxygen atom of nitro group with the loss of proton 


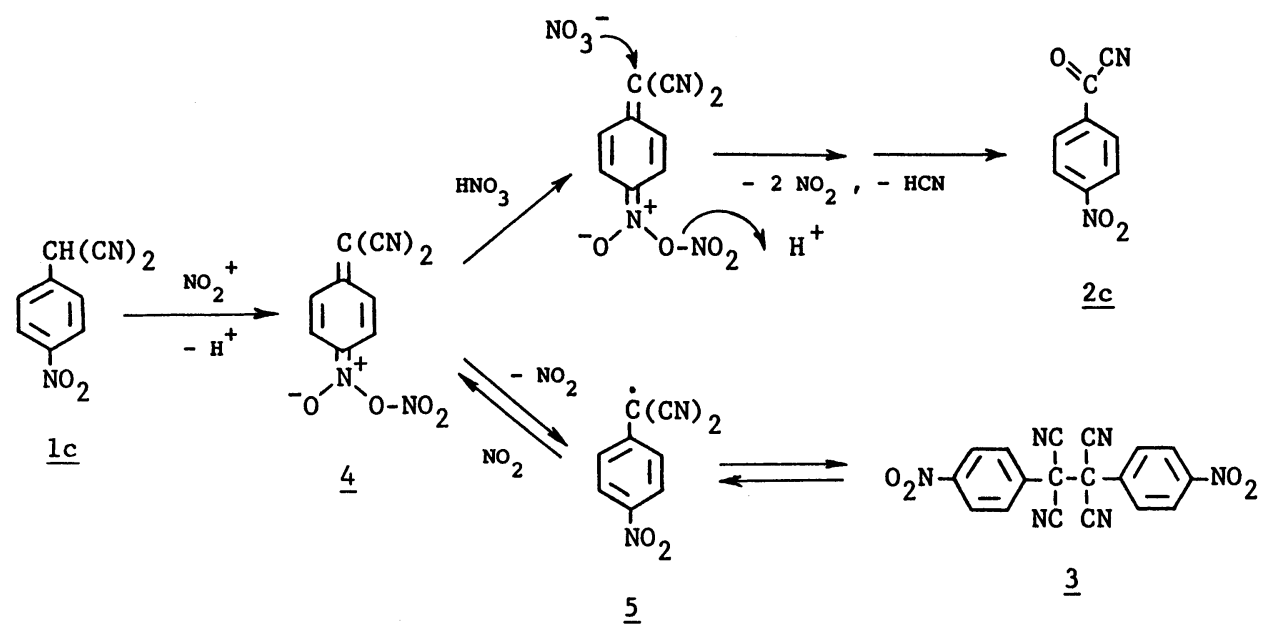

Scheme 1 .

Table 1. Benzoyl Cyanides Obtained from the Reaction of Arylmalononitriles with Nitric Acid

\begin{tabular}{|c|c|c|c|c|c|}
\hline & \multicolumn{2}{|c|}{ Arylmalononitrile $\mathbf{1}$} & \multirow{2}{*}{$\begin{array}{c}\text { Reaction } \\
\text { time/h }\end{array}$} & \multicolumn{2}{|c|}{ Benzoyl cyanide 2} \\
\hline & $\mathbf{R}^{1}$ & $\mathbf{R}^{2}$ & & $\operatorname{Mp}\left(\theta_{\mathrm{m}} /{ }^{\circ} \mathrm{C}\right)$ & Yield $/ \%$ a) \\
\hline $\mathrm{a}$ & $\mathrm{H}$ & $\mathrm{H}$ & 6 & $116-117$ & $77^{\mathrm{b})}$ \\
\hline b & $\mathrm{H}$ & $\mathrm{Me}$ & 8 & $50-51$ & 74 \\
\hline $\mathrm{c}$ & $\mathbf{H}$ & $\mathrm{NO}_{2}$ & 0.7 & $116-117$ & 85 \\
\hline $\mathrm{d}$ & $\mathrm{Cl}$ & $\mathrm{Me}^{2}$ & 6 & $126-129$ & 72 \\
\hline
\end{tabular}

a) Yields refer to the isolated compounds and are not optimized. b) Product was 2c.
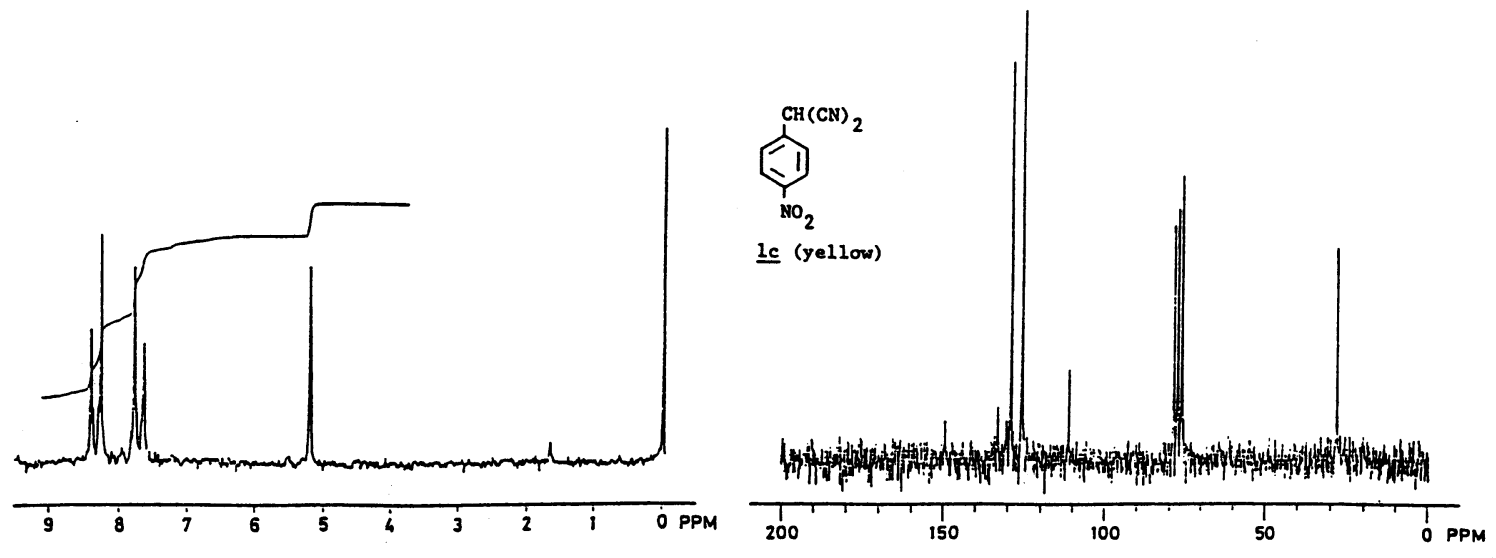

Fig. 1. ${ }^{1} \mathrm{H}$ and ${ }^{13} \mathrm{C}$ NMR spectra of $\mathbf{~ c}$ in chloroform- $d$.

from the side chain. The intermediate 4 then undergoes attack of oxygen nucleophile on the electrondeficient exo-carbon to form acyl cyanide $2 c$ or dissociates into a radical 5 and nitrogen dioxide via the homolytic fission of a nitrogen-oxygen bond as sketched in Scheme 1. A stabilized radical 5 is expected to be in equilibrium with the dimer 3 .

Dinitrile lc is usually prepared by the action of cyanogen chloride on 4-nitrophenylacetonitrile anion ${ }^{6)}$ or by the arylation of malononitrile anion with 4bromonitrobenzene. ${ }^{7)}$ It is described as pale yellow plates melting at $109-110^{\circ} \mathrm{C}$ and characterized by its remarkable acidity. ${ }^{7,8)}$ When this compound was prepared by the literature method, there was obtained a pale yellow crystalline solid, $\mathrm{mp} 108.5-109.5^{\circ} \mathrm{C}$. Its IR, ${ }^{1} \mathrm{H}$ and ${ }^{13} \mathrm{C}$ NMR, and UV spectra were all consist-
Table 2. Spectroscopic Data of the Yellow and Red Forms of 4-Nitrophenylmalononitrile (2c)

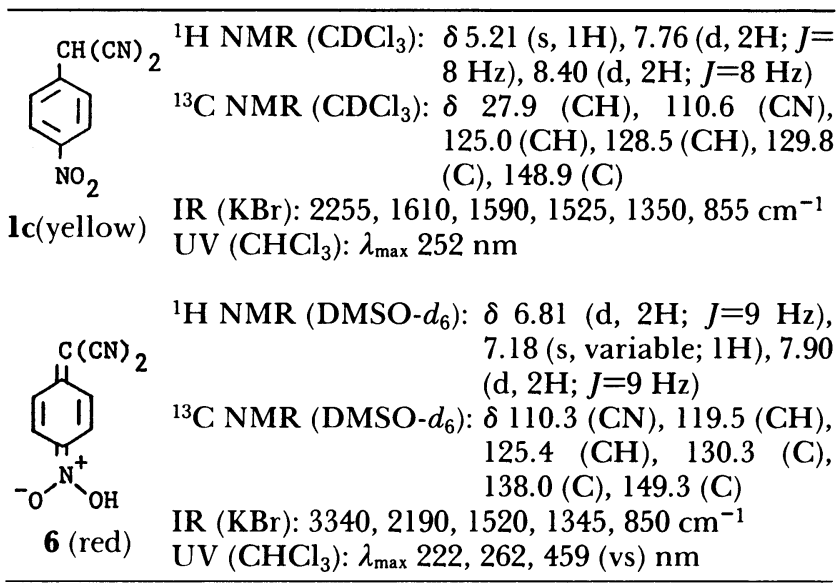



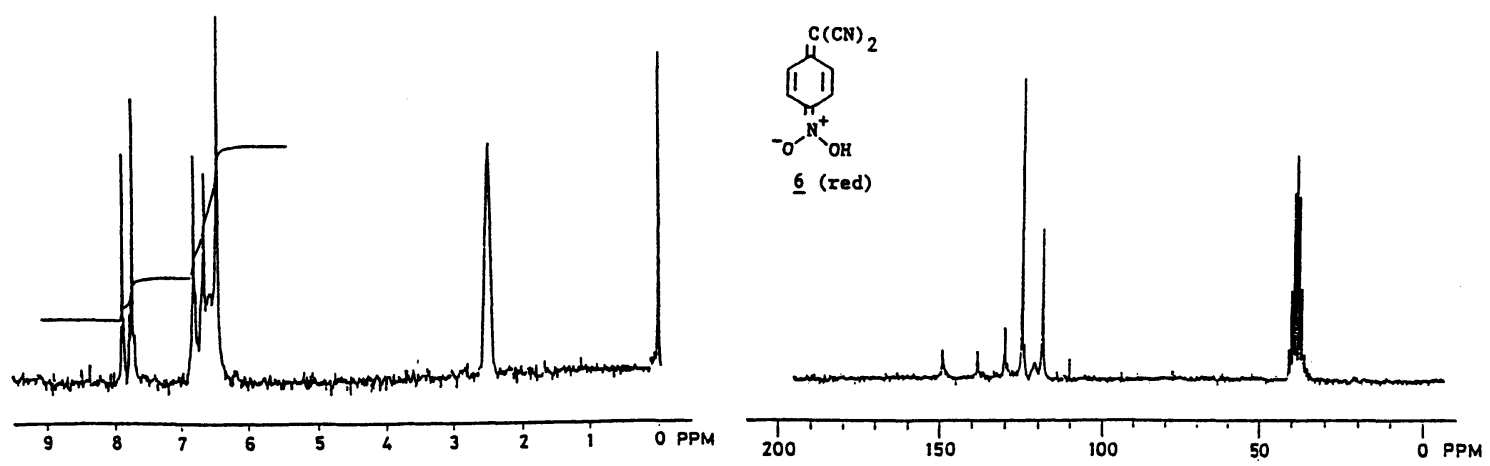

Fig. 2. ${ }^{1} \mathrm{H}$ and ${ }^{13} \mathrm{C}$ NMR spectra of 6 in DMSO- $d_{6}$.

ent with the aromatic structure lc (Table 2). When dissolved into methanol or DMSO, however, this yellow dinitrile developed a deep red color and the ${ }^{1} \mathrm{H}$ and ${ }^{13} \mathrm{C} N M R$ spectra of the solution thus obtained were completely different from those of chloroform or benzene solution (Figs. 1 and 2). A deep-colored methanolic solution was evaporated under reduced pressure to leave a dark red solid, which also exhibited an infrared spectrum very different from that of a pale yellow compound. The red dinitrile is soluble in acetone, DMSO, and methanol to form a red solution, but it is slightly soluble in benzene and chloroform to give a yellow solution. In contrast, the yellow dinitrile is soluble in most common organic solvents to give a yellow to deep red solution depending on the nature of solvent employed. Both dinitriles are interconvertible simply by choosing an appropriate solvent system. On the basis of spectroscopic and microanalytical data as well as their behaviors toward different solvent systems, a nitro structure lc was assigned to the yellow dinitrile and an aci-nitro structure 6 to the red one. Our finding represents an additional mode of nitro/aci-nitro tautomerism, which occurs through a long distance at the expense of aromatic stabilization of benzene nucleus.

\section{Experimental}

All melting points were determined on a hot-stage apparatus and are uncorrected. IR spectra were run as $\mathrm{KBr}$ pellets on a Hitachi 260-10 spectrophotometer and only prominent peaks are recorded. UV spectra were measured in chloroform with a Hitachi $220 \mathrm{~A}$ spectrophotometer. ${ }^{1} \mathrm{H}$ and ${ }^{13} \mathrm{C}$ NMR spectra were obtained on Hitachi R-600 and JNM-FX-100 spectrometers using TMS as an internal standard. Unless otherwise stated NMR data refer to deuteriochloroform solutions. Mass spectra were determined on a Hitachi M-80B mass spectrometer with $70 \mathrm{eV}$ ionizing current.

Arylmalononitriles were prepared by allowing the corresponding iodoarenes to react with malononitrile anion in the presence of copper(I) iodide in hot hexamethylphosphoric triamide (HMPA). ${ }^{9)}$ The following typical example illustrates the general procedure used in the synthesis of the dinitriles. In the preparation of lc, assistance by copper(I) catalyst is not necessary.
2,3,5,6-Tetrachloro-4-methylphenylmalononitrile (1d). A commercial $60 \%$ sodium hydride dispersion in mineral oil (ca. $4 \mathrm{~g}$ ) was washed three times by decantation with hexane and the remaining solid was covered with dry HMPA (10 $\mathrm{ml})$. A solution of malononitrile $(3.3 \mathrm{~g})$ in the same solvent $(10 \mathrm{ml})$ was added with stirring under nitrogen. After the cease of gas evolution, 2,3,5,6-tetrachloro-4-iodotoluene $(3.56 \mathrm{~g})$ was added, followed by copper(I) iodide $(2.0 \mathrm{~g})$, and the mixture was gradually heated to $85^{\circ} \mathrm{C}$ and kept at this temperature for $10 \mathrm{~h}$. TLC monitoring of the reaction mixture at this time showed no unreacted iodide. The black mixture was then quenched with dilute hydrochloric acid and the organic phase was extracted several times with ether. The extracts were combined, washed with aqueous sodium sulfite, and evaporated under reduced pressure. The crude product was chromatographed on silica gel using a hexanedichloromethane mixture as eluent to give dinitrile $\mathbf{l d}$ as a crystalline solid, $\mathrm{mp} 207-209^{\circ} \mathrm{C}$. Yield, $1.65 \mathrm{~g} \mathrm{(56 \% ).} \mathrm{MS}$ (70 eV) $m / z$ (rel intensity) $293\left(\mathrm{M}^{+}, 100\right), 264(36)$, and 258 (37); ${ }^{1} \mathrm{H}$ NMR: $\delta=2.66(\mathrm{~s}, 3 \mathrm{H})$ and 6.11 (s, $\left.1 \mathrm{H}\right)$; ${ }^{13} \mathrm{C}$ NMR: $\delta=20.67,25.97,109.20,131.57,132.22,134.27$, and 140.96; IR: $2240,1550,1440,1400,1385,1360,1135$, and $1000 \mathrm{~cm}^{-1}$. Found: $\mathrm{C}, 41.09 ; \mathrm{H}, 1.39 ; \mathrm{N}, 9.59 \%$. Calcd for $\mathrm{C}_{10} \mathrm{H}_{4} \mathrm{~N}_{2} \mathrm{Cl}_{4}$ : $\mathrm{C}$, 40.86; H, 1.37; N, 9.53\%.

Phenylmalononitrile (1a): $\mathrm{Mp} 67-68^{\circ} \mathrm{C} .{ }^{1} \mathrm{H}$ NMR: $\delta=$ $5.06(\mathrm{~s}, 1 \mathrm{H})$ and $7.48(\mathrm{~s}, 5 \mathrm{H})$; IR: 2250, 1490, 1450, 1010, 910 , and $725 \mathrm{~cm}^{-1}$. ${ }^{101}$

4-Methylphenylmalononitrile (1b): $\mathrm{Mp} 57-58^{\circ} \mathrm{C} .{ }^{1} \mathrm{H}$ NMR: $\delta=2.39(\mathrm{~s}, 3 \mathrm{H}), 4.93(\mathrm{~s}, 1 \mathrm{H})$, and $7.0-7.2(\mathrm{~m}, 4 \mathrm{H})$; IR: 2250, 1500, 1005, 805, and $755 \mathrm{~cm}^{-1}$. Found: C, 77.19; H, 5.11; $\mathrm{N}, 18.22 \%$. Calcd for $\mathrm{C}_{10} \mathrm{H}_{8} \mathrm{~N}_{2}$ : C, 76.90; $\mathrm{H}, 5.16 ; \mathrm{N}, 17.94 \%$.

4-Nitrophenylmalononitrile (1c): $\mathrm{Mp} 109-110^{\circ} \mathrm{C} .{ }^{1} \mathrm{H}$ NMR: $\delta=5.21(\mathrm{~s}, 1 \mathrm{H}), 7.76(\mathrm{~d}, 2 \mathrm{H} ; \mathrm{J}=8 \mathrm{~Hz})$, and $8.40(\mathrm{~d}$, $2 \mathrm{H} ; J=8 \mathrm{~Hz}$ ); IR: $2255,1610,1590,1525$, and $1350 \mathrm{~cm}^{-1}$. Found: $\mathrm{C}, 57.81 ; \mathrm{H}, 2.45 ; \mathrm{N}, 22.33 \%$. Calcd for $\mathrm{C}_{9} \mathrm{H}_{5} \mathrm{~N}_{3} \mathrm{O}_{2}$ : C, $57.76 ; \mathrm{H}, 2.69 ; \mathrm{N}, 22.45 \% .{ }^{6}$

Reaction of Arylmalononitriles with Nitric Acid. The procedure used in each of the reactions described was identical; therefore, only a typical example of these reactions will be reported in detail. The results are summarized in Table 1.

To a solution of 4-methylphenylmalononitrile (1b; 0.156 $\mathrm{g})$ in dichloromethane $(1 \mathrm{ml})$, nitric acid $(d=1.5 ; 0.5 \mathrm{ml})$ was added and the mixture was stirred at room temperature for several hours, during the course of which the initial slightly yellow color gradually deepened to yellowish green, then faded to light yellow after $5 \mathrm{~h}$. Liberation of nitrogen dioxide was observed. The mixture was diluted with water and the resulting turbid solution was extracted with dichloro- 
methane. The extract was washed three times with cold water, dried with sodium sulfate, and evaporated under reduced pressure to leave a pale yellow solid. The residue was recrystallized from hexane-chloroform to afford 4methylbenzoyl cyanide $(\mathbf{2 b})$ as colorless needles, mp 50$5{ }^{\circ} \mathrm{C}$. Yield, $0.108 \mathrm{~g}(74 \%) .{ }^{1} \mathrm{H}$ NMR: $\delta=2.49(\mathrm{~s}, 3 \mathrm{H}), 7.40(\mathrm{~d}$, $2 \mathrm{H}: J=8 \mathrm{~Hz}$ ), and $8.05(\mathrm{~d}, 2 \mathrm{H} ; J=8 \mathrm{~Hz})$; IR: $2215,1660,1595$, 1260 , and $975 \mathrm{~cm}^{-1}$. Found: C, 74.18; H, 4.89; N, 9.66\%. Calcd for $\mathrm{C}_{9} \mathrm{H}_{7} \mathrm{NO}$ : C, $74.47 ; \mathrm{H}, 4.86$; N, 9.65\%.

On heating with methanol, $\mathbf{2 b}$ was converted into methyl 4-methylbenzoate, identical with an authentic sample.

4-Nitrobenzoyl Cyanide (2c): $\mathrm{Mp} 116-117^{\circ} \mathrm{C} .{ }^{1} \mathrm{H}$ NMR: $\delta=8.41$ (br. s, 2H) and 8.43 (br. s, 2H); IR: 2215, 1680, 1525, 1345 , and $1230 \mathrm{~cm}^{-1}$. Found: C, 54.64; $\mathrm{H}, 2.29 ; \mathrm{N}, 15.71 \%$. Calcd for $\mathrm{C}_{8} \mathrm{H}_{4} \mathrm{~N}_{2} \mathrm{O}_{3}$ : C. 54.55, H, 2.29; N, $15.90 \%$.

2,3,5,6-Tetrachloro-4-methylbenzoyl Cyanide (2d): $\mathrm{Mp}$ 126-129 ${ }^{\circ} \mathrm{C} .{ }^{1} \mathrm{H}$ NMR: $\delta=2.63$ (s, 3H); IR: $2200,1700,1540$, 1350, 1340, 1240, 1160, 1055, and $920 \mathrm{~cm}^{-1}$. Found: C, 38.03; H. $1.09 ; \mathrm{N}, 4.71 \%$. Calcd for $\mathrm{C}_{9} \mathrm{H}_{3} \mathrm{NOCl}_{4}$ : C, 38.20; $\mathrm{H}, 1.07 ; \mathrm{N}$, $4.95 \%$.

Oxidative Coupling of 4-Nitrophenylmalononitrile to 1,2Bis(4-nitrophenyl)-1,1,2,2-tetracyanoethane. A solution of dinitrile 1c in dichloromethane was mixed with nitric acid and the green reaction mixture obtained was quenched with iced water after a few minutes. A pale yellow solid was collected by filtration and fractionally crystallized from tetrahydrofuran-ether. $\mathrm{Mp} 156-157^{\circ} \mathrm{C}$. Found: C, 58.06; H,
2.03; N, 22.27\%. Calcd for $\mathrm{C}_{18} \mathrm{H}_{8} \mathrm{~N}_{6} \mathrm{O}_{4}: \mathrm{C}, 58.07 ; \mathrm{H}, 2.17 ; \mathrm{N}$, $22.57 \%$.

The authors thank Advanced Instrumentation Center for Chemical Analysis, Ehime University, for NMR spectral determinations and elemental analyses.

\section{References}

1) The reaction of polysubstituted aromatics. Part LXII; Part LXI: H. Suzuki, H. Abe, N. Ohmasa, and A. Osuka, Nippon Kagaku Kaishi, 1982, 445.

2) J. R. Knowles and R. C. O. Norman, J. Chem. Soc., 1961, 2938.

3) B. F. Holleman, Chem. Rev., 1, 187 (1925).

4) B. Flürsheim and E. L. Holmes, J. Chem. Soc., 1928, 2230 .

5) For a review, see H. Suzuki, Synthesis, 1977, 217.

6) H. D. Hartzler, J. Am. Chem. Soc., 86, 2174 (1964).

7) M. J. Minch, N. Giaccio, and R. Wolff, J. Am. Chem. Soc., 97, 3766 (1975).

8) E. M. Arnett and E. B. Troughton, Tetrahedron Lett., 24, 3299 (1983).

9) H. Suzuki, T. Kobayashi, and A. Osuka, Chem. Lett., 1983, 589.

10) P. B. Russel and G. H. Hitchings, J. Am. Chem. Soc., 74, 3443 (1952); J. C. Hessler. Am. Chem. J., 32, 119 (1904). 